\title{
Oฆి ஜุข
}

\section{Thakur Ka Kuan, Munshi Premchand Translated into Odia by Jhuni Mallick}

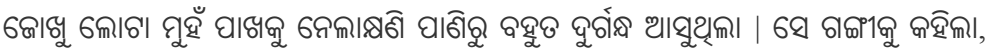

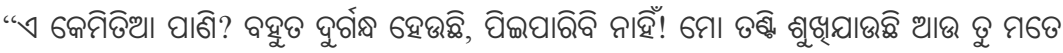

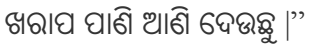

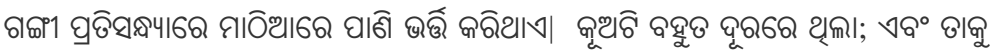

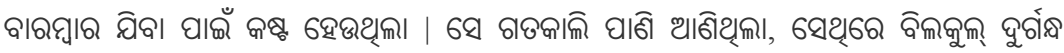

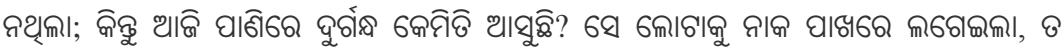

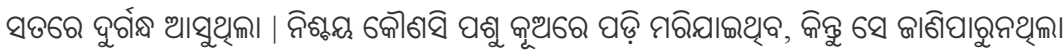
๑ก घเสิ ๆ|ฮิด 6๑ญัญ?

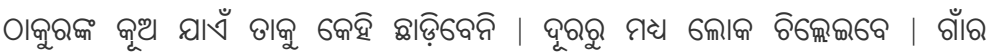

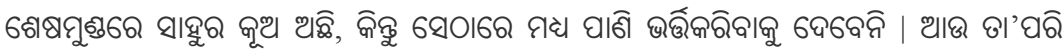

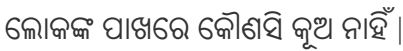

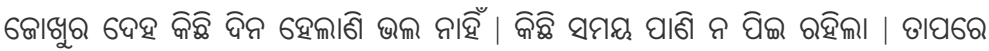

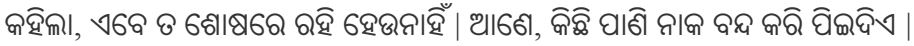

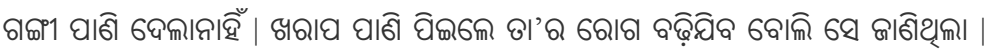

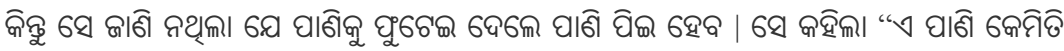

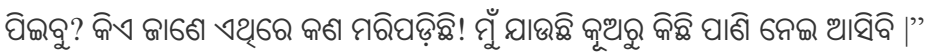

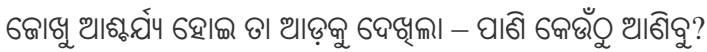




\section{Thakur Ka Kuan}

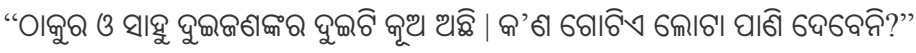

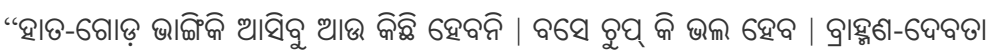

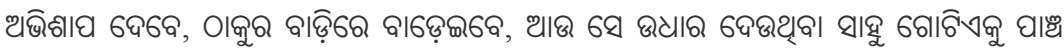

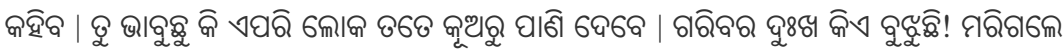

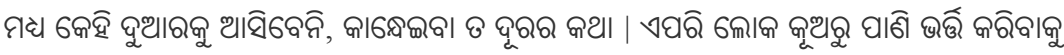
6९6६?"

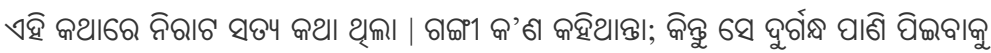

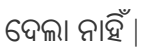

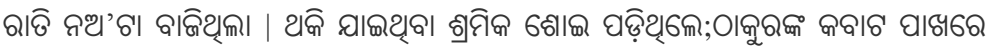

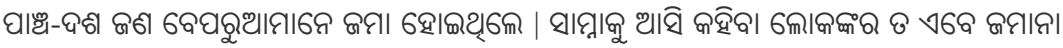

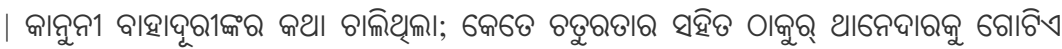

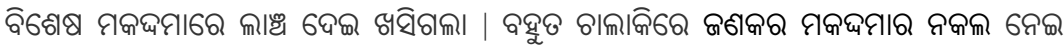

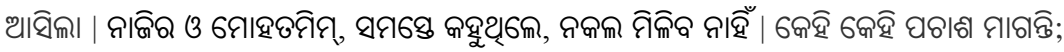

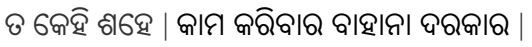

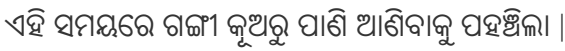

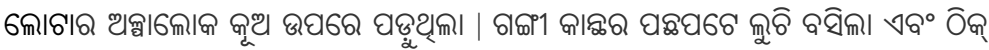

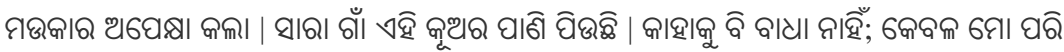

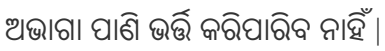

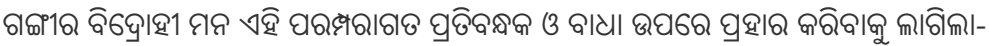

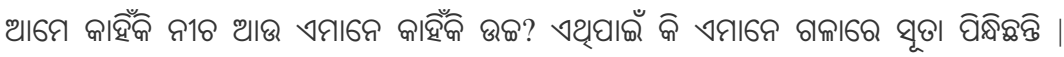

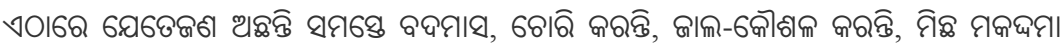

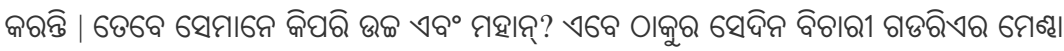

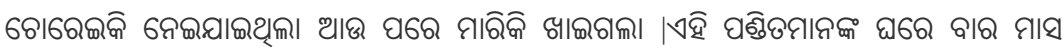




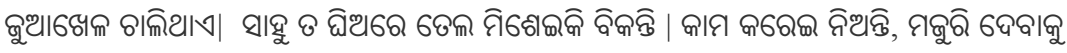

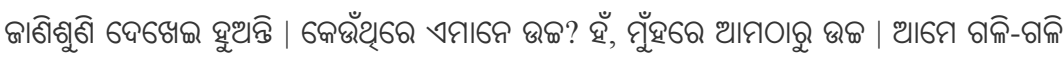

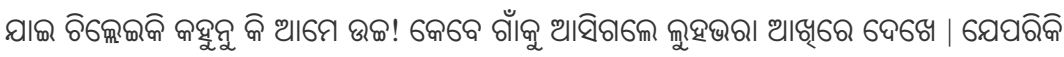

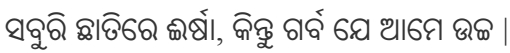

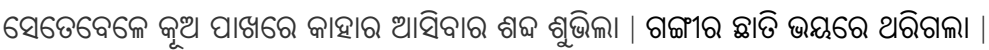

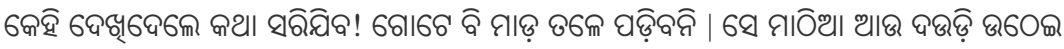

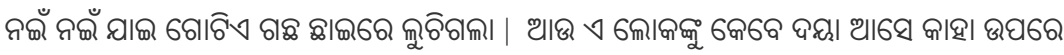

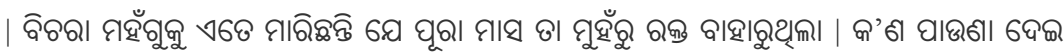

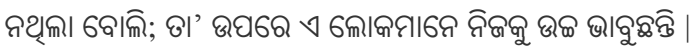

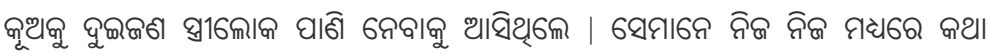
6๕ษ)ุุ

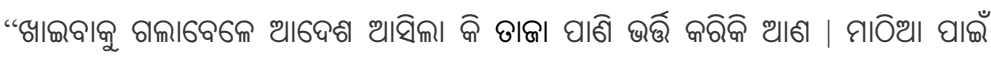

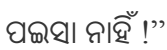

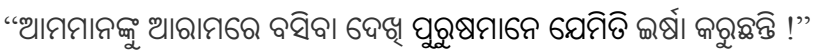

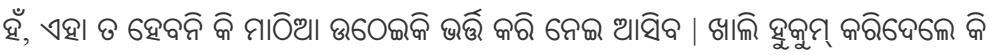

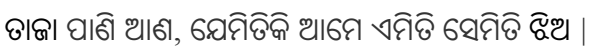

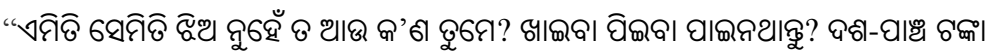

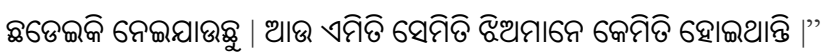

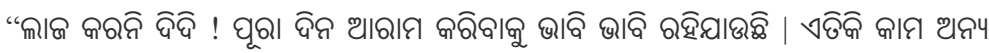

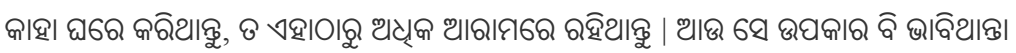

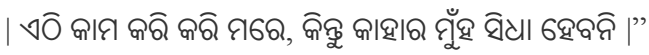




\section{Thakur Ka Kuan}

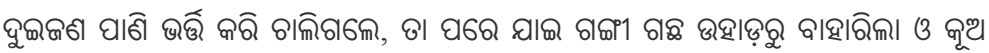

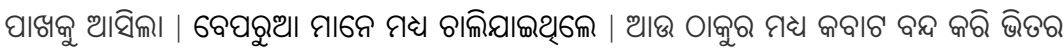

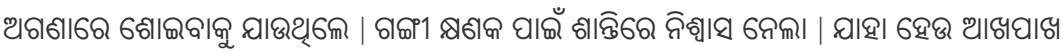

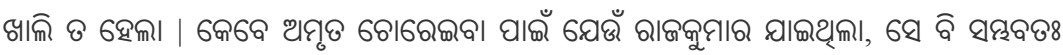

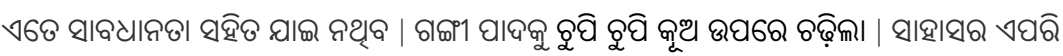

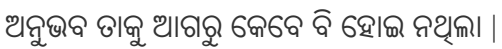

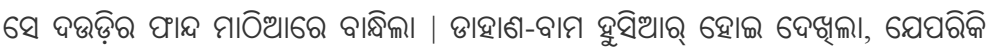

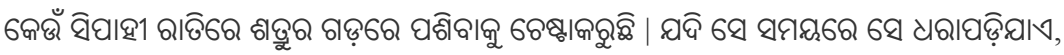

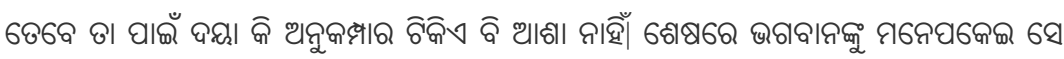

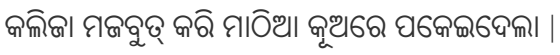

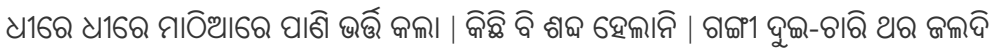

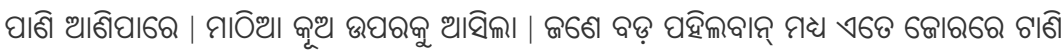
ઘાดิ ลથાઝ। |

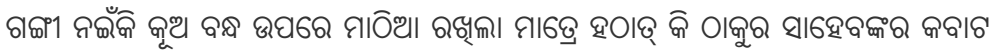

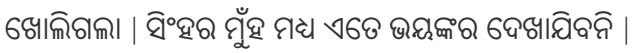

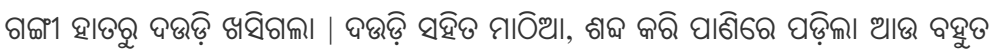

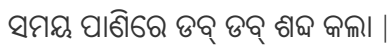

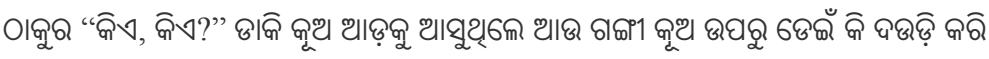
ઘ|ஐથุญ। |

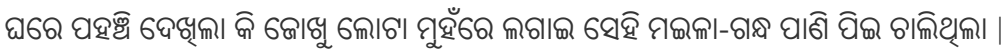

